\title{
ARE THE WATER TRIPS IN THE DRYLAND KENYA FOR SUSTAINABLE DEVELOPMENT, JOURNEYS IN VAIN OR TRIPS TO OBLIVION ${ }^{*}$ AFULLO, A.0. ${ }^{1}$ and DANGA, B.0. ${ }^{2}$ \\ http://dx.doi.org/10.4314/ejesm.v6i3.2
}

\begin{abstract}
Received 10th December 2012; accepted 18th March 2013

Kenya's households' (HH) water access status is appalling. As a gender based task, women and children make billions of trips to satisfy HH water needs, taking a heavy toll on societal growth and development. Kenya's 4872 randomly sampled HHs from six Arid and semi-Arid land (ASALs) counties were studied using interviews and focused group discussions. The aim was to determine the burden of water fetching in Kenya-ASALS. On a daily basis, HHs make 3.06 water trips of $49.42 \pm 0.36$ minutes, largely shouldered by females (2.69 trips); males (0.22); women (2.51); men (0.12) and children (0.43 trips). The 2.5 million Kenyan-ASAL households make 7,658,500 trips daily (2,795,352,500 annually). Of these, children make 395,477,500; women (2,287,637,500); and men (112,237,500 trips). With this kind of burden, the children and women are denied opportunity for self-development. Water supply mainstreaming is an urgent priority in Kenya-ASALS.
\end{abstract}

Key words: Water Supply, Sustainability, Gender, Development, Kenya ASALS

\section{Introduction}

Access to improved water is the $31^{\text {st }}$ article in the universal declaration of human rights, yet millions of people have no hope of access. Kenya's woman and children play important roles as collectors, users and managers of water (Simiyu and Afullo, 2011; Sengul (2010)), responsible for procuring, managing, and using water for drinking, cooking, washing, cleaning and bathing. As women and children play these roles, they forego opportunities for self-discovery as well as self and societal development. Partly due to this, Kenya is poorly ranked 143 rd out of 187 , with a Human development Index (HDI) of 0.509 (UNDP, 2011). The imbalanced global development challenges led to the coining of the concept of millennium development goals (MDGs). A total of 8 goals were listed, with six of them hinged on achieving universal water and sanitation (WATSAN) access (UNDP, 2006 and FAO, 2007). Water was assigned goal 7 and by 2010, only Sub Saharan Africa (SSA) was unlikely to meet it (WHO, 2012).

FAO (2007) attempted to provide a link between water and other MDGs. According to Sengul, (2010) accessibility to clean water has been a major challenge in the $21^{\text {st }}$ century. Women bear the highest costs of the environmental crisis because of their roles in providing water, food and energy. Water is essential for both life and health, and its supply and access is a key indicator of global development, forming an integral part of HDI assessment (UNDP (2006, 2011)). Hunter et.al (2010) observed that a safe, reliable, affordable, and easily accessible water supply is essential for good health. Ishakul et al. (2011) sought to determine whether water supply had contributed effectively to development of Nigerian, and realized that water-fetching was done by women.

The drudgery of water-fetching also affects the education of girls, time available for productive work and coping strategies (Gbolahan and Coster (2012). Nwankwoala (2011a) observed the role of all segments of society in improved rural water supply systems in Nigeria as an essential ingredient to achieve Vision 2020. Nwankwoala (2011b) emphasized localizing the strategy for achieving rural water supply. In Kenya's Mandera, water is largely a woman's job, fetched from far.

This study sought to determine the impact of the burden of water fetching in Kenya-ASALs. The specific objectives were

1. To establish the number of trips taken for fetching water

2. To estimate the man-years lost from fetching water

3. To assess the impacts of water fetching on development.

\footnotetext{
${ }^{1}$ North Central College, Naperville 60540, Illinois, USA.

${ }^{2}$ School of Agriculture, Department of Soil Science 


\section{Methodology}

Quantitative and qualitative methods were used. A pretested questionnaire was administered to consenting heads of $4872 \mathrm{HHs}$ in Kenya's Taita-Taveta (Coast), Makueni (Eastern) and Baringo / West Pokot counties (Rift valley) (table 1). Research assistants were trained, and tools piloted. In addition, 40 Key informant interviews (KII), observation and photography, secondary data, and 10 focused group discussions (FGDs) were used, targeting water users associations, community based organizations and government departments.

\section{Sampling and Sample Size}

Ten surveys were done in 4872 households between 2006 and 2010 in Kenya's ASAL. Using multi-stage sampling, with a sampling frame of over 10,000 HHs, a sample of $450(n=450)$ was randomly selected from each ASAL county, calculated as per the sampling error formula at
95\% confidence level and a design effect of 1.125. A comprehensive questionnaire was designed, pretested and administered to the HHs. The local community facilitators were used as key informants and in reconnaissance during which questionnaire administration strategies were designed. Through this, a target was met with a total of 4872 households being interviewed, out of the planned 4100-4950. These resulted in a series of sampling plans which were used as described below.

1: Three Kenyan Provinces Rift Valley, Eastern and Coast were purposively sampled for being ASAL (Figure 1)

2. Weighting was done with the number of Districts per province considered in a sample proportionate to a population (and area index). This gave Rift valley a figure of 160, Eastern 28 and Coast 33.

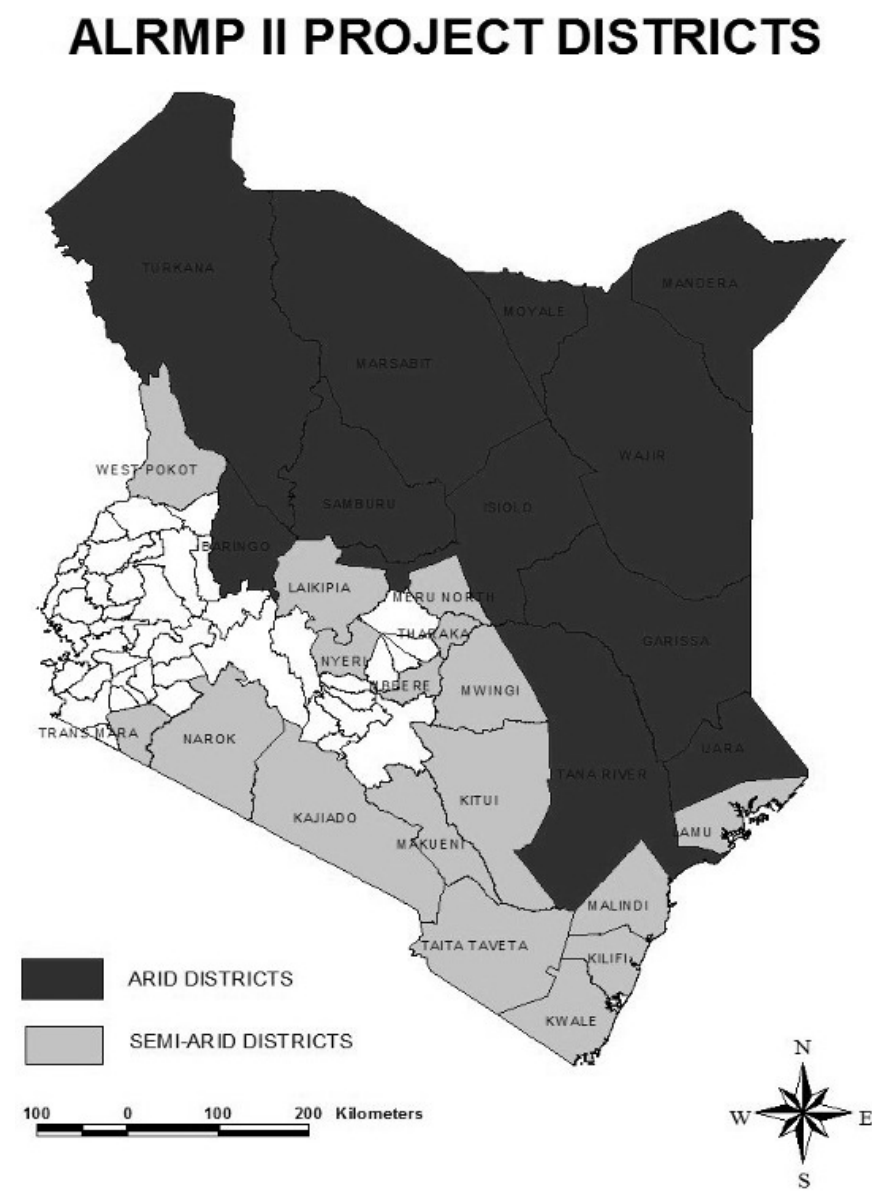

Figure 1 The study areas- Map of Kenya (source http://www.aridland.go.ke/index.php) 
Table 1 County sampling criteria- actual samples and sample size

\begin{tabular}{|c|c|c|c|c|c|c|}
\hline Province & Frequency & Percent & Survey Site & County & Frequency & Percent \\
\hline \multirow{3}{*}{ Rift valley } & \multirow{3}{*}{2626} & \multirow{3}{*}{53.9} & Mogotio & Baringo & 900 & 18.5 \\
\hline & & & Orwa & West Pokot & 825 & 16.9 \\
\hline & & & Ndabibi & Nakuru & 901 & 18.5 \\
\hline \multirow{2}{*}{ Coast } & \multirow{2}{*}{1346} & \multirow{2}{*}{27.6} & Taita Taveta I & Taita Taveta & 900 & 18.5 \\
\hline & & & Taita Taveta II & Taita Taveta & 446 & 9.2 \\
\hline Eastern & 900 & 18.5 & Makueni & Makueni & 900 & 18.5 \\
\hline Total & 4872 & 100.0 & & & 4872 & 100.0 \\
\hline
\end{tabular}

\section{Results and Discusion}

\section{Household Sizes and Characteristics}

A total of 4872 households in six Kenyan Arid and semi-arid (ASAL) counties were surveyed between 2008 and 2010. The mean Household sizes was $5.52 \pm 2.28$, with variations of: Makueni (6.15 \pm 2.18 ; Taita Taveta 2012 (4.97 \pm 2.31 ; Rift Valley / Nakuru $(4.93 \pm 2.28)$; Coast / Taita Taveta I (5.56 \pm 2.08$)$; Rift valley / Baringo $(5.71 \pm 2.52)$ and Rift valley / Pokot (5.54 \pm 2.09$)$ (table 2).

\section{Who Fetches Water In Kenya's Asals}

This study shows that $50.9 \%$ of the water is always fetched by a female, $36.6 \%$ by any member of the household; $5 \%$ always by male members of the household; and $4.4 \%$ always by children (boys: girls being 1:1.2). In only $3 \%$ is water in the house or brought by vendor. If the $36.6 \%$ is distributed equally among the gender, with $18.3 \%$ assigned to each, it would mean that men would have a $23.3 \%$ chance of fetching water, while women would have a $69.2 \%$ chance of fetching water. In this case, a woman is thrice likely to fetch water than a man. Water-fetching is therefore a woman's job, indicating, the MDGs, government water master plan and Vision 2030 are hardly achievable (GoK, 2006, 2007).

This result in figure 2 concurs with a number of past studies. According to WHO (2012), for families without house or yard water, it is women who fetch water. Surveys from 45 developing countries show that this is the case in almost $67 \%$ of HHs (this study comes with $69 \%$ ), while in $25 \%$ HHs it is men who collect water (This study comes close with $23.3 \%$ ). These are statistically similar figures, meaning that Kenya performs like East Africa and SSA. Gbolahan and Coster (2012) Nigeria study found out that in $90 \%$ of the HHs the women usually collect the water from the source, as compared to $64 \%$ in all developing countries. WHO (2012) found that in $12 \%$ of the HHs, children do water fetching, with girls under 15 years being twice as likely as boys of same age. Water does not seem to be an item of child abuse in Kenya, with only $4.4 \% \mathrm{HHs}$ having them responsible for fetching water. Therefore, a Kenyan child in ASAL is 2.7 times less likely to fetch water compared with any other child in the SSA. Gender bias in water management is not exclusively African. Chan (2006) realized that 61.3\% HHs in Georgetown (Malaysia) and 56\% HHs in Pattaya (Thailand) mothers were the main water managers. Whereas $0 \%$ men fetched water when $\mathrm{HH}$ supply was interrupted in Georgetown, $20 \%$ did so in Pattaya. In Georgetown its $77.8 \%$ women while the remaining $22 \%$ child (Chan, 2006).

Table 2 Demographic characteristics of households in study area

\begin{tabular}{|c|c|c|c|c|c|c|c|c|}
\hline Province & District & $\begin{array}{l}\text { Mean } \\
\text { HH size }\end{array}$ & $\begin{array}{l}\text { Std. } \\
\text { Deviation }\end{array}$ & $\begin{array}{l}\text { Median } \\
\text { HH size }\end{array}$ & $\begin{array}{l}\text { Std. } \\
\text { Error } \\
\text { Mean }\end{array}$ & Sum & Minimum & Maximum \\
\hline Eastern & Makueni & 6.15 & 2.177 & 6.00 & .073 & 5539 & 1 & 16 \\
\hline \multirow[t]{3}{*}{ Rift Valley } & Baringo / Mogotio & 5.71 & 2.524 & 5.00 & .084 & 5124 & 1 & 16 \\
\hline & Nakuru / Ndabibi & 4.93 & 2.282 & 5.00 & .077 & 4322 & 1 & 16 \\
\hline & West Pokot / Orwa & 5.54 & 2.093 & 5.00 & .074 & 4413 & 1 & 13 \\
\hline \multirow[t]{3}{*}{ Coast } & Taita Taveta I & 5.56 & 2.080 & 5.00 & .069 & 4994 & 1 & 14 \\
\hline & Taita Taveta II & 4.97 & 2.307 & 5.00 & .109 & 2216 & 1 & 14 \\
\hline & Total & 5.52 & 2.283 & 5.00 & .033 & 26608 & 1 & 16 \\
\hline
\end{tabular}




\section{Who fetch water for Household use (\%)}

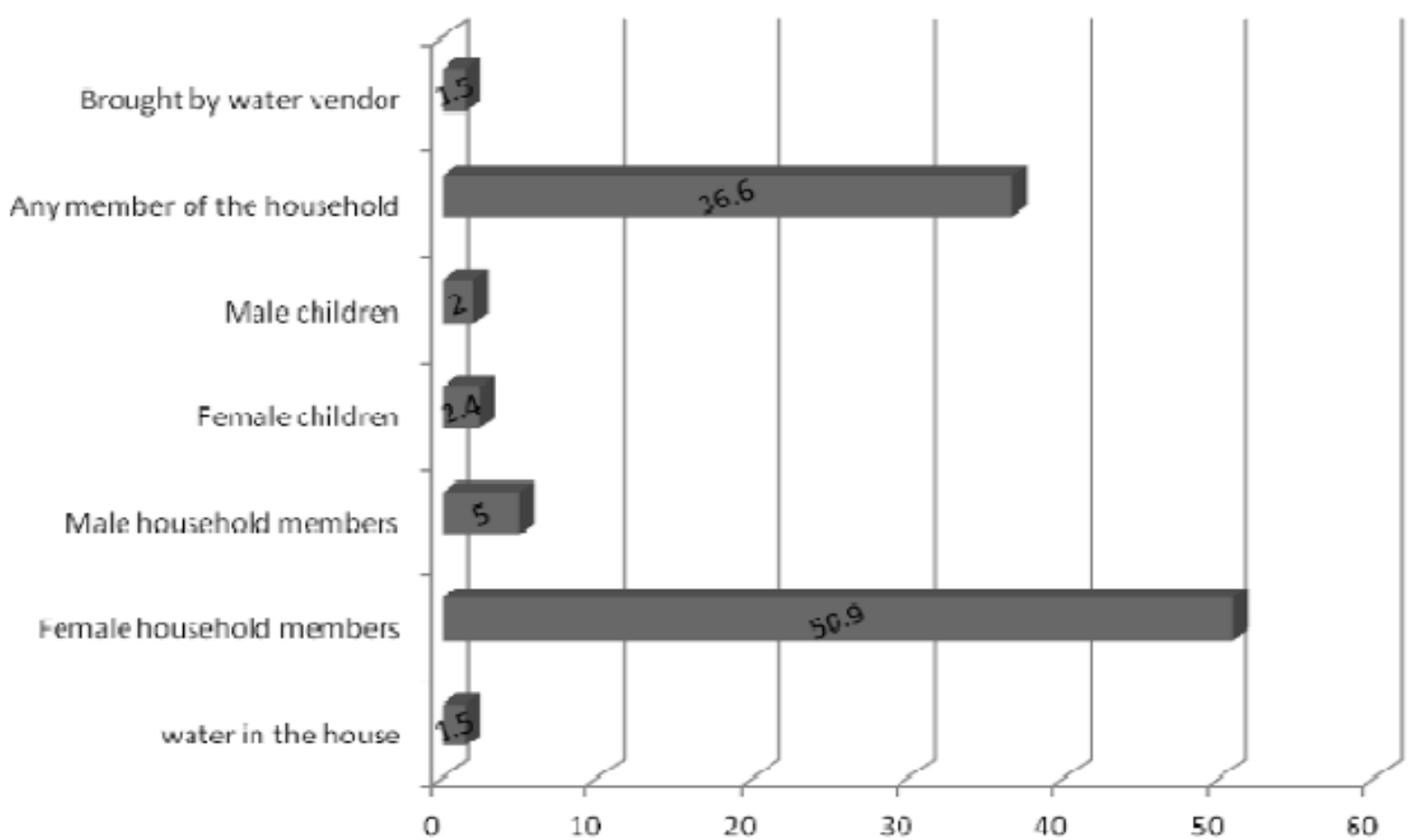

Figure 2 Who fetches water in Kenya's ASALS

Mean Time Taken on One Trip to Fetch Water in Kenya's ASALS

In one trip for water, $26.7 \%$ of the HHs took under 30 minutes; $29.5 \%$ took 30-60 minutes, while $42.8 \%$ took over an hour. Whereas time spent on water-fetching depends on the source, Gbolahan and Coster (2012) opine that diseases and distance also affect choice of water source. This study finds $\mathrm{HH}$ fetching water within under 30 minutes is still the minority. This is perfectly in agreement with the view that water collection trips of over 30 minutes are most prevalent in Africa and ASAL countries such as Mongolia and Yemen (WHO, 2012). With Kenya classified as one with more than $25 \%$ of its HHs exceeding 30 minutes on a water trip, this research finds the KenyaASALs are just at the threshold at $26.7 \%$, which has no statistical difference with WHO's $25 \%$. Whereas the half-hour threshold is critical in many respects, the most significant of this arise from a WHO assertion that those exceeding 30 minutes round trip progressively collect less water and eventually fail to meet their family's drinking water needs. In SSA, 33\% of the improved drinking sources that are not piped on premises need a collection time exceeding 30 minutes (WHO, 2012). According to WHO (2012) rural Africa studies, $51 \%$ use water from unimproved source (67\% for Kenya's ASALs from this study); $17 \%$ improved sources more than 30 minutes ( $24.1 \%$ in Kenya's ASALS - this study); $25 \%$ improved source under 30 mins $(8.9 \%$ in KenyaASALS -this study); and $7 \%$ piped water. In a Nigeria (Gbolahan and Coster (2012)), 42.5\% of the $\mathrm{HHs}$ walk $100 \mathrm{~m}$ from their home to water sources while $47.5 \%$ take under 20 minutes; $67 \%$ queue for under 30 minutes for water; $35 \%$ take 34 trips daily; and $66 \%$ take under 1 hour fetching water. In Mozambique, under $10 \% \mathrm{HHs}$ walk more than $1 \mathrm{~km}$ for water, depicting a better picture than Kenya (UNICEF, 2009).

\section{Correlations and Associations}

The associations showing Kendal and Spearman correlation indicate the following statistically significant correlation:

1. Kendall test shows no statistically significant correlation between time taken per trip and per capita water use, while the 
spearman correlation test indicates a weak, indirect statistically significant relationship of -0.097

2. Household water use and time taken on a trip for water $(r=-0.076 \mathrm{Kendal}$, and -0.097 Spearman). This shows a negative but significant relationship. As the time to fetch one trip of water increases, the amount of water used per person decreases. This is expected.

3. Time taken to fetch water is negatively but weakly correlated with $\mathrm{HH}$ vulnerability to hunger (Kendall's correlation value of 0.101; Spearman's correlation coefficient of -0.107). Thus as the water closer, there is prospect for irrigation, and thus the household is unlikely to suffer from lack of food as the distance from water decreases.

These correlations compare favorably with other studies. Gbolahan and Coster (2012) found out the duration of trekking and women's HH size showed weak positive correlation of $\left(\mathrm{r}=.264^{*}, \mathrm{~N}=115\right.$, $\mathrm{P}<0.05)$ but strong relationship of $\mathrm{P}=$
$0.00(\mathrm{P}<0.05)$. This implies that as $\mathrm{HH}$ size increased, more water trips are done. This may become burdensome, tiring as well as stressful, thus, impacting on their health and economic activities.

\section{Burden of Water Fetching: Time Lost By Women in Water Fetching}

Statistical analysis revealed that the mean time taken on a round trip for water was $49.42 \pm 0.36$, Standard deviation of 24.99 , and a median of 45 minutes, with special variations as follows:

(a) Province: Taita-Taveta County: $33.77 \pm$ 0.63; Baringo County: 51.97 \pm 0.46; and Makueni $65.48 \pm 0.59$.

(b) Among individual sampled divisions, Makueni recorded $65.48 \pm 0.59$; followed by Baringo's Mogotio (56.82 \pm 0.76; Nakuru's Ndabibi (49.93 \pm 0.82$)$; Pokot's Orwa (48.71 \pm 0.81$)$; Taita-Taveta I $(35.45 \pm 0.77)$ and Coast / Taita-Taveta II $(30.37 \pm 1.11)$ Minutes.

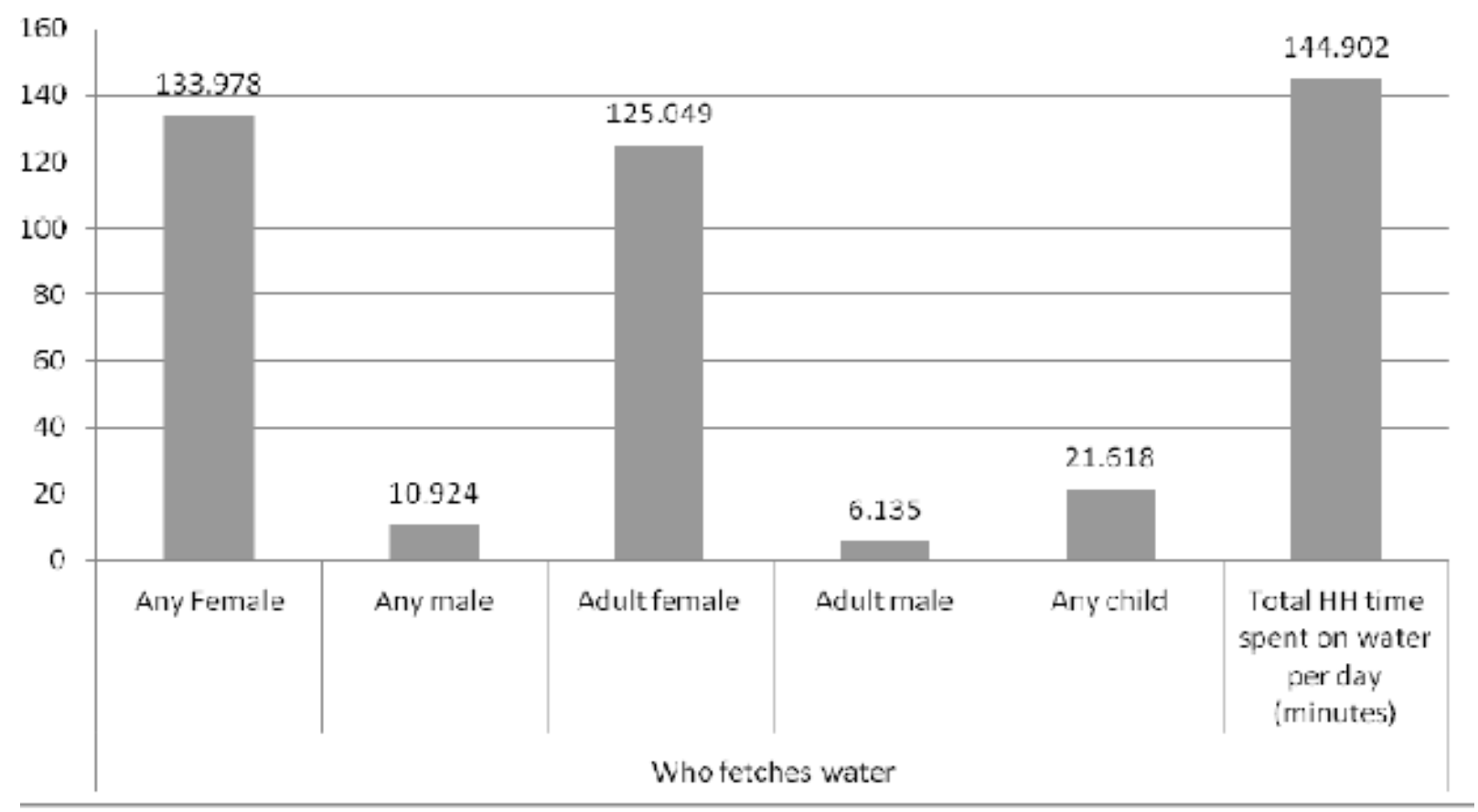

Figure 3 Daily household time spent on water-fetching (Minutes) 
Each HH spends 144.902 minutes daily fetching water. With at least 2.5 million $\mathrm{HHs}$, Kenya-ASALs spend 689.222 years daily on water fetching. With 125.049 minutes fetching water daily per $\mathrm{HH}$, women in Kenya-ASALs spend 689.222 years daily, and children $37,531.25$ days (102.83 years daily). In terms of trips, with a mean of 3.0634 daily-trips/HH, the Kenyan-ASAL HHs make 7,658,500 daily-trips $(2,795,352,500$ trips annually). Of these, children 395,477,500 dailytrips; women 2,287,637,500; and men 112,237,500 trips. These are sufficient to under develop a country, since the energies are not put in a useful activity.

\section{Burden of Water Fetching: Trips Taken to Fetch Water by Women}

The Kenyan makes, within 95\% confidence limits, 2.984 \pm 0.0792 or 2.905-3.0634 trips of water daily, each taking 49.42 minutes, implying a total of 2.53 hours daily. Reducing the number of trips would impact health by: affecting farm work (17.4\%); farm size (12.1\%); cause exhaustion (15.9\%); causes (water scarce) diseases (19.8\%); low farm yield $(14.2 \%)$; loss of farm income $(13.8 \%)$; affects labour availability $(6.8 \%)$ because of associated health impacts of reduced water use
(Gbolahan and Coster, 2012) . In rural Benin, girls ages 6-14 spend an average of one hour a day collecting water compared with 25 minutes for boys. Malawi has large variations in the amount of time allocated for water collection based on seasonal factors, but women consistently spend 45 times longer than men on this task (UNDESA, 2010; and Mughogho and Kosamu (2012)). Through simple random sampling of 120 women respondents in Ogun (Nigeria), Gbolahan and Coster (2012) recognized the impact of water scarcity and drudgery of water collection on women's health coming from multiple trips to fetch water. This Kenyan ASAL study finds that in a day, a female makes 2.69 trips (3.38 TaitaTaveta; 2.14 in Rift valley; 3.30 - Makueni); males make 0.22 trips daily ( 0.28 Taita-Taveta; 0.18 Rift valley; 0.27 Makueni); women make 2.51 trips daily (3.16 Taita-Taveta; 2.00 Rift valley; 3.09 Makueni); men make 0.12 trips daily (0.16 Taita-Taveta; 0.10 Rift valley; and 0.15 Makueni) while children make 0.43 trips daily (0.55 Taita-Taveta; 0.34 Rift Valley and 0.53 Makueni) (Figure 4). On the average, a female in Kenya's ASALS is 12 times more likely to fetch water than a male.

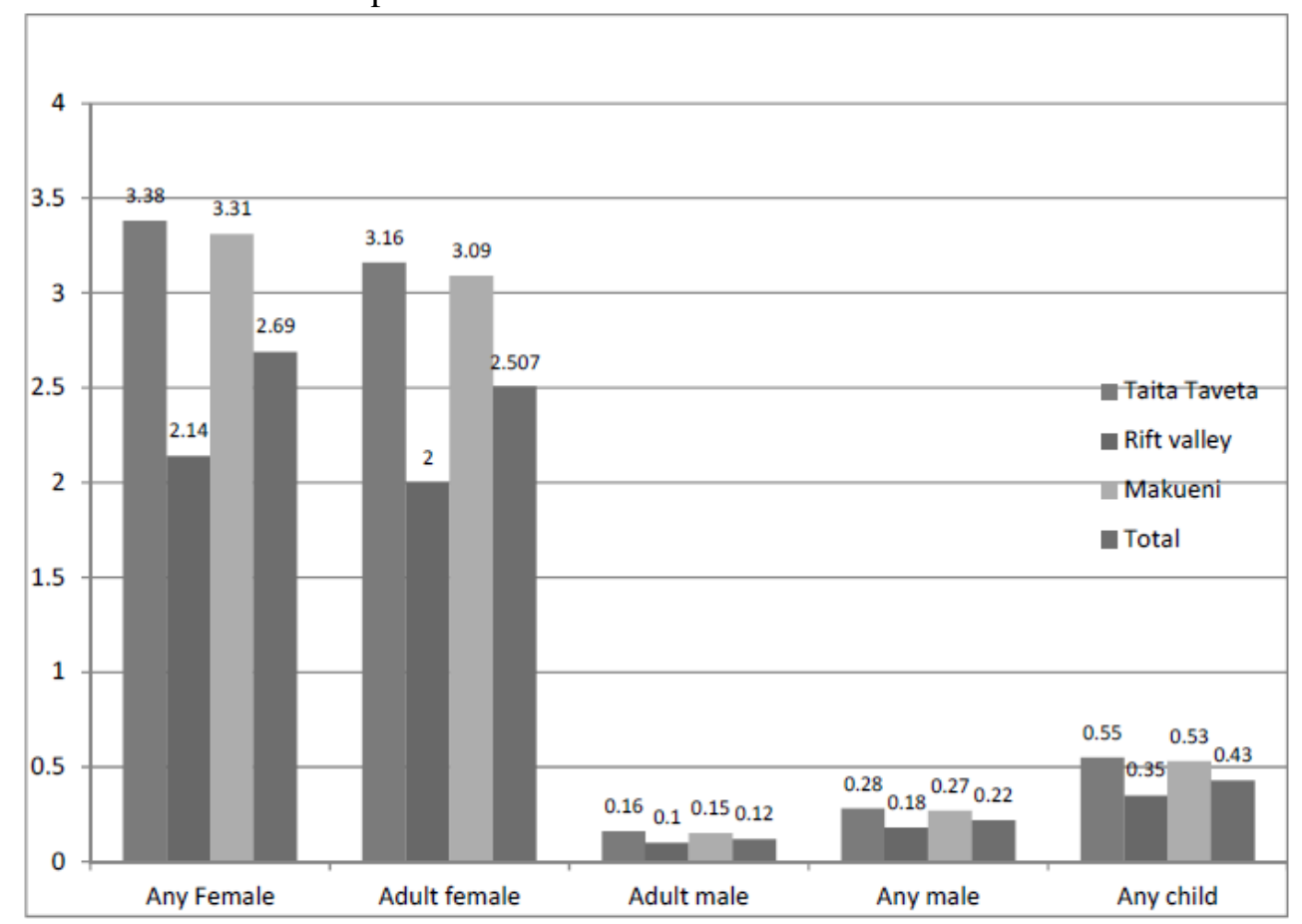

Figure 4 Number of daily water trips made by each member of household 
That water fetching is a woman's job is not strange to Kenya (GWA 2006). UNDESA (2010) makes telling observations in different countries on water fetching as a source of gender inequality. In Tanzania, school attendance are $12 \%$ higher for girls in homes located under 15 minutes from a water source than in homes more than an hour away. Attendance rates for boys were less affected by distance from water sources (Burke and Beegle, 2004). Figure 5 (UNDESA, 2010) shows that children are responsible for collecting water in $12 \%$ of $\mathrm{HHs}$, with girls under 15 years being twice as likely to carry this responsibility as boys of same age. Research in SSA suggests that women and girls in low-income countries spend 40 billion hours a year collecting water (UNDESA 2010). In Africa, $90 \%$ of the work of gathering water and wood, for the household and for food preparation, is done by women. Providing access to clean water close to the home can dramatically reduce women's workloads, and avail time for other economic activities. For girls, this time can be used to attend school (UNDESA (2010). With this kind of time lost on avoidable activities, it is the responsibility of humanity to ensure access attainment of MDG goal on water a priority. For Kenya, achievement of its progressive and ambitious Vision 2030 relies on it achieving gender balance (GoK, 2007).

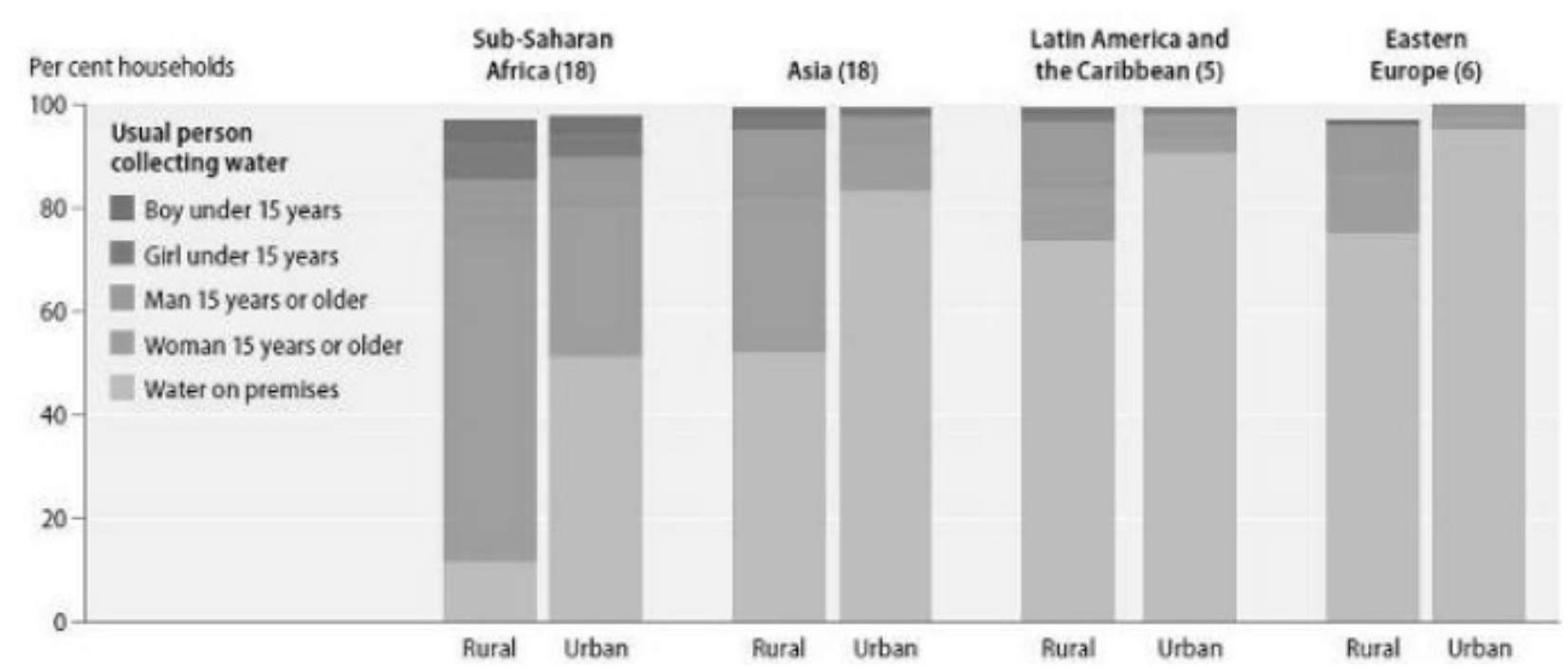

Figure 5 distribution of household by person responsible for water fetching by region (Source: UNDESA, 2010)

Approximately 2.5 milion $\mathrm{HHs}$ in Kenya are ASALs (GoK, 2009). With a mean of 3.0634 trips per household daily, the ASAL households in Kenya make 7,658,500 trips daily. This equals $2,795,352,500$ trips annually. Of these, children make 395,477,500 trips; women make 2,287,637,500; while men make 112,237,500 trips.

\section{Opportunity Cost of Water Fetching}

Water fetching takes just under 50 minutes per trip for a Kenyan ASAL HHs (table 3), with 70\% of these borne by women, thereby denying them time for other activities. Gbolahan and Coster (2012) observe that the greatest symptom of marginalization and powerlessness of rural women is lack of time to perform their tasks and ensure sufficient leisure time to maintain their health The extent to which this impacts them depends on the water source. Close sources are fairly convenient, while sources requiring more than 30 minutes' walk cause a lot of pain, and affects level of productivity. They manifest as pressures on women's time, income, nutrition and health, social support networks, and knowledge. Gbolahan and Coster (2012) stressed that there is widespread understanding of the impact of water scarcity on women's health, and the drudgery of water collection on girls' education. 
Table 3 Mean Time spent to fetch water per trip (Minutes)

\begin{tabular}{rcccc}
\hline Coast & Rift valley & Eastern & Total \\
Mean time to fetch water (Minutes) & 34.69 & 52.08 & 65.57 & 49.88 \\
SE & & & & .171 \\
Amount of water used per person daily & 22.98 & 13.3 & 19.55 & \\
\hline
\end{tabular}

\section{Hours spent on water in Africa and what is lost in return}

In SSA, 40 billion hours are wasted annually carrying dirty water. Women trapped in this situation have little time for other activities (UNICEF (2004). According to Gbolahan and Coster (2012), one of the constraints to women productivity and welfare in the agricultural sector is the lack of WATSAN which result in morbidity and mortality in the developing world. The greatest symptom of marginalization and powerlessness of rural women is lack of time not only to perform their tasks, but to ensure sufficient leisure time to maintain their health, which affects their productivity (Gbolahan and Coster (2012).With just under $80 \%$ stating they feel tired after water collection, the stress involved significantly affects women engagement in other economic activities (Gbolahan and Coster (2012). Because men's work is considered a part of the productive economy of paid labour, it is generally prioritized for infrastructure investments while women's jobs are largely labor intensive (Gbolahan and Coster (2012).

Gbolahan and Coster (2012) observe that water scarcity has tremendous impact on women health, and the drudgery of water collection has cascading impact on the education of girls, on the time available for productive work and on the coping strategies at the household and community level. Gbolahan and Coster (2012) observe that convenient sources of safe water are of enormous importance to improve human health, agricultural labour productivity, hence income generation by rural women. This would imply that inconvenient sources eg those far away can hardly support productivity. The writer further stressed that a major benefit from better access to safe water is that the time spent fetching water from distance sources and preparing such water for human use can be engaged instead in other productive activities, attending to farm, school, or technical training, tending children's health and education needs or simply rest and recuperation. This also indicates that women would embark on frequent trips daily to the source of water in order to satisfy their household water needs in the event of water scarcity or if water is not readily available in the area (Gbolahan and Coster (2012). It is clear women cannot develop with burden of water on their heads.

\section{Implications to Health}

In a Nigeria, Gbolahan and Coster (2012) caution that the implication of the result is not only in the distance to the source of water, but more heavily the stress involved in collecting water, which has considerable implication for women health. Ahmed (2002) inferred that poor women lack of access to water has a direct impact on their time, income, and health. According to Gbolahan and Coster, (2012), the health of those who fetch water from a source away from the $\mathrm{HH}$ is threatened in three general ways: (i) by exposure to water-based diseases at the source (for exam vectors at or near the source (ii) by exposure to accidents, drowning, attack, and assault at and on the way to and from the water source; and (iii) by skeletal injuries caused by carrying heavy loads repeatedly over long periods of time. This is in support of WHO / UNICEF (2005) statement that the quantity of water collected and used by $\mathrm{HHs}$ has an important influence on health. The UNDP's Human Development Report of 2006 highlights issues of coping with water scarcity, and emphasizes the challenge of the twenty-first century. The poor rely solely on unprotected sources which are susceptible to diseases, yet households without access to safe drinking water are vulnerable to many health problems (Ishakulet al, 2011; Onda, et al, 2012 and Rob et al, 2012.). Studies show close statistical correlation between water scarcity, water quality and diseases prevalence. The most striking risks of poor water quality and water scarcity on the health are waterborne diseases and water based diseases (Gbolahan and Coster 2012). Correlation showed significant relationship between daily trip and duration of trekking to sources of water $(r=.24 * *$; $\mathrm{N}=115 \mathrm{P}<0.01)$ and a very strong relationship of $\mathrm{P}=0.00(\mathrm{P}<0.01)$ and between duration of 
trekking and women's household size $\left(\mathrm{r}=.26^{*}\right.$, $\mathrm{N}=115, \mathrm{P}<0.05)$ and a very strong relationship of $\mathrm{P}=0.00(\mathrm{P}<0.05)$. Gbolahan and Coster $(2012)$ concluded that increased access to improved water supply would assist in the maximization of their potential; reduce stress and diseases.

\section{Association between Water fetching and poverty (lack of food)}

Water fetching has a heavy toll on individuals and households. Pearson's correlation test indicate a negative but significant association between time spent fetching water and family lacking food (as exhibited by a coping strategy it used when had no food), at a correlation of -0.086 . Another statistically significant relationship exists between family poverty and per capita water use, with a direct correlation coefficient of +0.119 . This would mean that as per capita water availability improves, HHs are likely to more disposable income for food purchase and have a wider scope of coping strategies. This would mean that if water was cheaply available, HHs would have some resources to produce and / or purchase food. On the other hand, lack of water denies the HHs means for food purchase and food production.

\section{Conclusion}

1. $2.984 \pm 0.0792$ water trips are made by Kenyan-ASAL households. Of this, a female (women and girls) makes 2.69 trips males make 0.22 water trips daily; women make 2.51 trips daily; men make 0.12 trips daily while children make 0.43 trips daily.

2. The 2.5milion HHs in Kenya-ASALs makes $7,658,500$ trips daily $(2,795,352,500$ trips annually). Of these, women make 2,287,637,500; children make 395,477,500 while men make $112,237,500$ trips.

3. With each $\mathrm{HH}$ spending 144.902 minutes daily, Kenya-ASALs waste 689.222 years daily on water fetching. With women spending 125.049 minutes fetching water daily per household, this implies women in Kenya-ASALs spend 594.792 of the 689.222 years daily on water-fetching. The child spends $37,531.25$ days; or 102.83 years daily water-fetching.

4. Water is a major female job in KenyaASALS and is a leading barrier to progress of women in these communities

\section{References}

Burke, K. and Beegle, K. (2004), Why children aren't attending school: the case of North Western Tanzania. Journal of African Economies, 13(2), 335-355

Chan, N.W. (2006), A Comparative Study Of Water Resources Usage By Households In Georgetown-Malaysia And Pattaya-Thailand. Iran. J. Environ. Health. Sci. Eng., 3(4), 223-228

FAO (2007), Coping with water scarcity. Challenge of the twenty-first century. UN-Water, FAO

Gbolahan, A.O. and Coster, A.S. (2012), Impact of Water Scarcity and Drudgery of Water Collection on Women' Health in Ogun of Nigeria. J Hum Ecol., 39(1), 1-9.

GOK (2006), Kenya National Water. Development Report / Master plan. Ministry of water and irrigation, Nairobi

GoK (2007), Kenya: Vision 2030. Kenya. Ministry of Planning and National Development,

Government of Kenya

GWA (2006), Mainstreaming Gender in Water Management. Resource Guide. United Nations Development Programme (UNDP), Gender and Water Alliance (GWA).

Ishakul, H.T., Rafee, M.1.M., Ajayi, A.P. and Haruna, A. (2011), Water Supply Dilemma in Nigerian Rural Communities: Looking towards the Sky for an Answer. Journal of Water Resource and Protection, 3, 598-606.

Hunter, P.R., MacDonald, A.M., Carter, R.C. (2010), Water Supply and Health. PLoS Med 7(11):e1000361.doi:10.1371/journal.pmed.100036 Journal of Water Supply and Health 7(11)

Mughogho, B.U.G. and Kosamu, I.B.M. (2012), Water supply arrangements in developing countries: A case study of Blantyre City, Malawi. African Journal of Environmental Science and Technology, 6(2), 94-103.

Nwankwoala, H.O. (2011a), The Role of Communities in Improved Rural Water Supply Systems in Nigeria: Management. Model and Its Implications for Vision 20:2020.Journal of Applied Technology in Environmental Sanitation, 1 (3): 295-302.

Nwankwoala, H.O. (2011b), Localizing the strategy for achieving rural water supply and sanitation in Nigeria. Afr.J.Environ.Sci.Technol. 5(13), 1170-1176. 
Onda, K., LoBuglio, J. and Bartram, J. (2012), Global Access to Safe Water: Accounting for Water Quality and the Resulting Impact on MDG Progress. Int. J. Environ. Res. Public Health, 2 (9), 880-894.

Rob, E.S.B., Stephen, W.G., Jim, A.W., Hong, Y.S.P. and Jamie, K.B. (2012),Accounting for water quality in monitoring access to safe drinking-water as part of the Millennium Development Goals: lessons from five countries. Bulletin of the World Health Organization. 90(3), 228-235A.

Sengul, H. (2010), Sustainable Water Management: A Case Study on Saving Behaviour of Turkish Women for Domestic Water Usage. European Journal of Social Sciences Volume12, Number 3(2010)

Simiyu, S. and Afullo, A. (2011), Effects of interventions on childhood diarrhoeal Morbidity in Kenya. Books on demand (BoD) Publishers, VDM
Verlag Dr. Müller e.K. ISBN 978-3-639-32524-9, paperback, 112 Pages. Published online. UNDESA (2010). World's Women 2010. Trends and Statistics.

UNDP (2011). Human development index. UNDP. UNDP (2006). Water and development: water and MDGs- Water scarcity and the MDGs. Human Development Report 2006.

UNICEF (2009): WASH BASELINE SURVEY MOZAMBIQUE 2009: Mozambique

WHO (2012) WHO progress on sanitation and drinking water. 2012 update. Progress on sanitation and drinking water: 2010 update. WHO/UNICEF Joint Monitoring Programme (JMP), 2010. Additional perspectives

World Health Organization and UNICEF (2005) WHO/UNICEF Joint Monitoring Programme for Water Supply and Sanitation. Water for life: making it happen. Publications of the WHO. 